\title{
Genetic effects of inflammation markers on exhaled nitric oxide in schoolchildren with asthma: A twin study
}

\author{
Anna Hedman ${ }^{1}$, Ralf Kuja-Halkola ${ }^{1}$, Anne Örtqvist ${ }^{2}$, Marianne van Hage ${ }^{1}$, Catarina \\ Almqvist $^{2}$, and Björn Nordlund ${ }^{2}$ \\ ${ }^{1}$ Karolinska Institute \\ ${ }^{2}$ Karolinska Institutet
}

June 4, 2020

\begin{abstract}
Background: Exhaled nitric oxide and blood eosinophils are clinical asthma type 2 markers in use. Immunoglobulin E (IgE) is often involved in the inflammation associated with atopic asthma. The effect of both blood eosinophils and allergenspecific IgE on exhaled nitric oxide levels is not completely understood. Twin-design studies can improve understanding of the underlying contribution of genetically and/or environmentally driven inflammation markers in asthma. Our aim was to disentangle the covariance between asthma and exhaled nitric oxide into genetic and environmental contributions that can account for inflammation markers in a paediatric population. Methods: This population-based, cross-sectional twin study enrolled 612 monozygotic (MZ) and same-sex dizygotic (DZ) schoolchildren. Multivariate structural equation modelling was utilized to separate the covariance between asthma and exhaled nitric oxide into genetic and/or environmental effects, taking allergen-specific IgE level and blood eosinophil count into account while controlling for confounding factors. Results: The cross-twin/cross-trait correlations had a higher magnitude in the MZ twins than in the DZ twins indicating that genes affect the association. The likelihood ratio test for model fitting resulted in the AE model as the most parsimonious. A majority, $73 \%$, of the phenotypic correlation between asthma and exhaled nitric oxide, $\mathrm{r}=0.19(0.05-0.33)$, was attributable to genetic effects which mainly was due to the allergen-specific IgE level. Conclusions: This study indicate that the association between asthma - exhaled nitric oxide in children is to a large extent explained by genetics via allergen-specific IgE-level but not blood eosinophils. This might partly explain the clinical heterogeneity in this group. A next step could be to include allergen-specific IgE level in multivariate omic-studies.
\end{abstract}

\section{Introduction}

Asthma is the most common chronic disease in children ${ }^{1}$ and it is defined as an obstructive and often underlying airway inflammatory disease ${ }^{2}$. In allergic asthma, allergen exposure and allergic reaction leads to type 2 (T2) inflammation ${ }^{3}$ and clinical available markers to measure possible inflammation are exhaled nitric oxide $\left(\mathrm{FE}_{\mathrm{NO}}\right)$, immunoglobulin E ( $\left.\mathrm{IgE}\right)$ sensitization and blood eosinophils ${ }^{3,4}$.

$\mathrm{FE}_{\mathrm{NO}}$ is easy to measure, and its level corresponds directly with asthma and inflammation in the bronchial epithelium $^{5}$. It is widely used in clinical care and is introduced to reflect asthma with T2 inflammation mediated by allergic reactions, eosinophilia and production of allergen-specific $\operatorname{IgE}$ antibodies ${ }^{6}$. $\mathrm{FE}_{\mathrm{NO}}$ can therefore aid asthma diagnosis, and, if correctly applied and interpreted, identify patients at risk of exacerbation ${ }^{7}$. In clinical practice, generalized cut-off values of $\mathrm{FE}_{\mathrm{NO}}$ have so far been difficult to translate to individual patients due to unknown contribution of factors that influence the $\mathrm{FE}_{\mathrm{NO}}$ value, such as allergenspecific IgE level, blood eosinophil counts ${ }^{8}$, tobacco smoke ${ }^{9}$, upper airway infection, age, and height ${ }^{10}$.

The interest of measuring the number of blood eosinophils has increased in recent years since the introduction of anti-interleukin-5 therapy for severe eosinophil asthma ${ }^{11}$. High blood eosinophils appear to be related 
to poor asthma control, hospitalisation ${ }^{12}$ and reduced lung function development in adults ${ }^{13}$. Hence, both $\mathrm{FE}_{\mathrm{NO}}$ and blood eosinophil count reflects ongoing $\mathrm{T} 2$ inflammation. However, the different mechanisms involved in regulating these biomarkers seems different. $\mathrm{FE}_{\mathrm{NO}}$ levels is activated by interleukin-4/-13 and blood eosinophil count by interleukin- $5^{14}$. The inflammatory contribution of blood eosinophil counts on the asthma-FE $E_{\mathrm{NO}}$ association is not completely understood and debated ${ }^{12}$. $\operatorname{IgE}$ is an important clinical biomarker, which is often involved in the inflammation associated with atopic asthma, the most common form of asthma in children ${ }^{15}$. The airway inflammation involved in atopic asthma is recognized with both increased total $\mathrm{IgE}$ concentration and an elevated $\mathrm{FE}_{\mathrm{NO}}$ fraction, as well as activation of eosinophilic granulocytes ${ }^{15,16}$. In sensitized children, blood eosinophil count have been shown to be associated with increased level of $\mathrm{FE}_{\mathrm{NO}}{ }^{17}$. Still, the relative contribution of allergen-specific IgE level and blood eosinophil count on $\mathrm{FE}_{\mathrm{NO}}$ in children with asthma is not established.

Twin studies provide a unique method for determining the contribution of genetic and environmental sources of variation in a disease or phenotype ${ }^{18}$. The multivariate twin design can aid in the estimation of the same genetic and/or environmental factors influence different diseases and intermediate phenotypes ${ }^{19}$. This can broaden our understanding of asthma biomarkers and inform gene-mapping efforts ${ }^{20}$. We have previously shown that the association between asthma and $\mathrm{FE}_{\mathrm{NO}}$ was mainly explained by genetics and sensitization ${ }^{21}$. Therefore, our goal here was to further disentangle the association between asthma and $\mathrm{FE}_{\mathrm{NO}}$, by estimate the relative contribution of genetic and/or environmental effects from both allergen-specific IgE level and blood eosinophils. These potential shared genetic origins and environmental contributions will be studied in a multivariate twin study, thereby avoiding inflated type 1 error by multiple testing.

\section{Methods}

\section{Study design and study sample}

The Swedish Twin Study on Prediction and Prevention of Asthma (STOPPA) is a population-based, crosssectional twin study on childhood asthma in discordant, concordant, and healthy concordant twins ${ }^{22}$. The study participants were recruited from the Child and Adolescent Twin Study in Sweden (CATSS) ${ }^{23}$, a study initiated in 2004 that included all twins born from July 1992 and onwards, identified through the Swedish Twin Registry ${ }^{24}$. Validated questions on asthma ever (yes/no) and wheezing (current or after three years of age) were used to identify 9- to 14-year-old twins discordant and concordant for asthma or wheeze and healthy control twins according to the International Study of Asthma and Allergies in Childhood (ISAAC) 25. Monozygotic (MZ) and same-sex dizygotic (DZ) twin pairs who were raised together were recruited to STOPPA from all parts of Sweden and distributed throughout the whole year. The study population $(\mathrm{n}=$ 752 ) was classified as asthma concordant (31\%), asthma discordant (38\%), and healthy concordant (31\%), according to the recruitment algorithm of asthma status, as described in detail elsewhere ${ }^{22}$. One twin pair had unknown zygosity, and 138 individuals had missing data on inhaled corticosteroid steroid (ICS) use. The final analytic sample consisted of 612 individuals (81.4\% of the study population with full information on all covariates). The study was approved by the Regional Ethical review board in Stockholm, Sweden. Informed consent was obtained from all the participants and their parents.

\section{Variables}

Asthma. All twins and their parents completed questionnaires. The parental questionnaire, which has previously been validated against health care registers with good agreement ${ }^{26}$, included questions on the parent's lifestyle, background, and medical history, followed by a section on each twin's general health status, lifestyle, and medical history. Everyone that replied positively to the ISAAC validated parental question 'Does he/she have, or has he/she had asthma?' 23,25 was then directed to other asthma-related questions and 'reported current asthma' was then defined as reporting positively to the question 'Does he/she still have asthma?' 22 .

$F E_{N O}$. Exhaled nitric oxide was measured during an exhalation of at least 6 seconds at a flow of 50 $\mathrm{ml} / \mathrm{s}\left(\mathrm{FE}_{\mathrm{NO}}\right)$, measured with a hand-held electrochemical analyzer (NIOX Mino, Aerocrine, Solna, Sweden) according to the guidelines ${ }^{27}$. The average integer value of $\mathrm{FE}_{\mathrm{NO}}$ (parts per billion) was recorded based 
on two consecutive measurements if they differed by less than $5 \%$ or based on three measurements if they differed by $>5 \%$.

Sensitization to airborne allergens. More than $90 \%$ of the participants underwent blood sampling, and serum was analysed for IgE antibodies to Phadiatopß ${ }^{28}$, Thermo Fisher Scientific, Uppsala, Sweden, a screening test for sensitization to a mix of common inhalant allergens (birch, timothy, mugwort, cat, dog, horse, house dust mites [Dermatophagoides pteronyssinus and farina], and mold [Cladosporium herbarum]). Sensitization was regarded as a level of [?] $0.35 \mathrm{kU}_{\mathrm{A}} / \mathrm{L}$ corresponding to a fluorescence intensity of 168 response units and this defined the categorical (1/0) IgE positive variable. The numeric IgE level to Phadiatop(r), here termed the allergen-specific IgE level, was used as a continuous IgE variable and has been described previously ${ }^{29}$. IgE values below the level of quantification of $0.1 \mathrm{kU}_{\mathrm{A}} / \mathrm{L}$ were assigned a value $0.09 \mathrm{kU}_{\mathrm{A}} / \mathrm{L}$, and values above $100 \mathrm{kU}_{\mathrm{A}} / \mathrm{L}$ were set at $100 \mathrm{kU} \mathrm{A} / \mathrm{L}$, as described elsewhere ${ }^{30}$. All samples were analysed at the Department of Clinical Immunology and Transfusion Medicine at the Karolinska University Hospital Solna, Sweden.

Eosinophils. Samples of venous blood were collected, and the numbers of blood eosinophils $\left(1 \times 10^{9}\right.$ counts/L) were counted at the local cites of Clinical Chemistry Laboratory.

Inhaled corticosteroids. Parents confirmed inhaled corticosteroid (ICS) treatment by answering yes to the questions 'Does he/she have, or has he/she had asthma?' and 'Has your child used ICS treatment regularly during the last 12 months?'

Zygosity. Data on zygosity were retrieved from the CATSS study. A majority of the twins had their zygosity determined by DNA analysis (84.3\%), with the remaining assessed via an algorithm of five questions on twin similarity, a validated technique to determine zygosity with at least $95 \%$ accuracy ${ }^{23}$.

Age. Information on age was collected from the questionnaires and is included as a covariate in the analyses.

Socioeconomic status (SES). As a proxy for SES, we used the parental (maternal or paternal) highest education retrieved from the questionnaire.

Any parental asthma. To assess the parental history of asthma, we collected the following item from the questionnaires: 'Does the mother/father have asthma?' and created a new variable 'any parental asthma,' based on whether either the mother or father or both had asthma.

Parental current smoking. Smoking was assessed from the questionnaire with the following question: 'Does the mum/dad smoke?'

\section{Statistical Analyses}

We analysed asthma, $\mathrm{FE}_{\mathrm{NO}}$, allergen-specific IgE level, and eosinophils, in a four-variate twin model. In this model, the covariance between variables within individuals, as well as the covariance between twins in pairs, are explicitly modelled in structural equation models. Asthma was analyzed as a binary variable and adjusted for age and sex. The data for $\mathrm{FE}_{\mathrm{NO}}$, allergen-specific IgE level, and eosinophils were all logtransformed to obtain a distribution closer to normal, and adjustments were done for ICS, age and sex. Due to the sampling scheme, the population may have a skewed distribution (compared to the source population) of investigated variables; thus, we re-weighted all analyses according to sampling probability.

\section{Assumptions testing}

First, a saturated model was fitted, which included separate estimates for means, prevalence rates, variances, and covariances between 'twin 1' and 'twin 2,' according to random assignment for order in pairs and separately between MZ and DZ twin pairs. We then proceeded to fit a model where we assumed symmetry within each zygosity, i.e., the twin order was not associated with means/prevalences and variances or with within-individual covariance between the traits, named "Symmetric". Finally, a model where means and variances were additionally assumed to be the same across zygosities was fitted corresponding to the basic assumptions needed for a quantitative genetic model, named "Assumption."

Observed correlations 
We presented correlations from the "Symmetric" model described above. The phenotypic correlations, $\mathrm{r}_{\mathrm{ph}}$, were based on the within-twin/cross-trait correlations. Intra-class correlations (ICC) are the correlations between the same variable measured in one twin and in his/her co-twin (i.e., cross-twin/within-trait). If the absolute value of ICC is larger in MZ twins than in DZ twins, this indicates that genes are involved in the association. The cross-twin/cross-trait (CTCT) correlations represents the correlations between one variable in one twin and another in the co-twin. If the absolute value of the CTCT is larger in MZ twins than in DZ twins, this implies that genes influencing both traits (at least partly) overlap. Pearson correlations were calculated for the associations between continuous traits, while tetrachoric for binary (asthma) and biserial correlations were calculated for both binary and continuous traits.

\section{Quantitative genetic model}

Based on the differences in genetic similarity for twins with different zygosities, MZ twins have a correlation of 1 for additive genetic effects (A), representing the combined effect of alleles at a locus and across loci that add up, whereas DZ twins have a correlation of $0.5^{31,32}$. Dominance genetic effects ( $\mathrm{D}$ or $d^{2}$ ) also contribute to twin pair similarity and the index interaction of gene alleles at the same locus (dominance), and are assumed correlated 1 between MZ-twins and 0.25 between DZ-twins. Furthermore, both types of twins are assumed to have an equal correlation of 1 for environmental effects that both twins share (C or $\left.c^{2}\right)$, such as perinatal and home environment, whereas unique environmental effects that twins in pairs do not share $(\mathrm{E}$ or $e^{2}$ ), such as accidents, are modelled with a correlation of 0 between twins. Thus, a higher correlation in MZ twins than in DZ twins would represent the effect of the higher proportion of genes shared among MZ twins ${ }^{33}$.

The multivariate genetic model estimates the genetic and environmental contributions to the phenotypic correlation between asthma and $\mathrm{FE}_{\mathrm{NO}}$ and the degree that can be accounted for by sensitization to aeroallergens and blood eosinophils. The phenotypic correlations were decomposed into combinations of A, D, C, and E, depending on which model was fitted. We fitted a series of structural equation models estimating the maximum-likelihood genetic and environmental variance components of variables, and the covariance between these. We performed likelihood ratio tests to find the best-fitting model.

We were interested in the correlation between asthma and $\mathrm{FE}_{\mathrm{NO}}$ and what potentially could affect this correlation in terms of genetic and environmental influences from other factors. Therefore, we proceeded to fit a four-variate "Cholesky model" to disentangle the sources of variance and covariance into genes and environment. In a Cholesky model, the order the variables appear is important; the "left" variables influence the variables to the "right," but not vice versa ${ }^{34}$ (see Figure 1) to allow estimation of the influence (i.e., genetic and/or environmental) of allergen-specific IgE level and eosinophils on the association between asthma and $\mathrm{FE}_{\mathrm{NO}}$. Since we were interested if allergen-specific IgE level and eosinophils could influence asthma and and $\mathrm{FE}_{\mathrm{NO}}$ we decided to model the variables in this order.

We fitted an ACE model, i.e., a model with A, C, and E sources of variance and covariance. We also fitted an ADE model, AE model, and CE model. We tested whether the nested models had poorer fits to the data using likelihood ratio tests. We also used the Akaikes Information Criterion (AIC) to assess the model fit. The AIC favors model parsimony and allows for comparisons across non-nested models. In addition, we compared other models with the ACE model (base) to assess model fit.

Figure 1 shows the Cholesky (here, the AE model is taken as an example, AE=additive genetic effects and unique/unshared environmental effects) by the observed variables (allergen-specific IgE level, eosinophils, asthma, and $\left.\mathrm{FE}_{\mathrm{NO}}\right)$ in relation to the unobserved latent factors $\left(\mathrm{A}_{1-4}\right.$ and $\left.\mathrm{E}_{1-4}\right)$, which are connected by the paths $\mathrm{a}_{11-44}$ and $\mathrm{e}_{11-44}$. Thus, the variance in, and covariance between, asthma and $\mathrm{FE}_{\mathrm{NO}}$ may be explained by the variance in allergen-specific $\operatorname{IgE}$ level and eosinophils, but not vice versa. Analyses were performed using the statistical software $\mathrm{R}^{35}$, version 3.6.1, and the package OpenMx ${ }^{34}$, version 2.15.5.

Additional details on calculated contributions to the correlations between asthma and $\mathrm{FE}_{\mathrm{NO}}$ are provided in the Online Supplemental material. 


\section{Results}

Table 1 gives an overview of the study population which had a mean age of about 12.5 years in both groups and with $58 \%$ males in the current asthma group. The percentage of any parental asthma was higher in the asthma group (46\%) than in the group reported no current asthma (16\%). The geometric means of $\mathrm{FE}_{\mathrm{NO}}$ and the allergen-specific IgE level were higher (18 and 2.3 respectively) in the asthma group than in the no current asthma group (12.9 and 0.3, respectively). The mean blood eosinophil count was higher in the asthma group ( 0.4 vs. 0.3 ), but the reported ICS was lower in the no current asthma group, at $0.2 \%$, than in the asthma group, at $44 \%$.

Here, we will only present results from models using the continuous variable allergen-specific IgE level to maximize statistical power. The Online Supplemental material shows results for the dichotomous variable IgE positive.

\section{Observed correlations}

The "Symmetric" model provides estimates of correlations, as estimated for MZ and DZ independently, and as all twins together (Table 2).

Table 2 present observed maximum likelihood correlations. Most $\mathrm{r}_{\mathrm{ph}}$ correlations were statistically significantly different from 0 , and about the same magnitude in both the MZ and DZ twins (except for the correlation between eosinophils and asthma which was 0.29 and significant in MZ twins but was -0.05 and non-significant in DZ twins), indicating that all variables are associated within individuals. All ICCs were statistically significantly different from 0 and higher in the MZ twins than in the DZ twins, indicating a heritable component for the univariate measures. All CTCTs had a higher magnitude in the MZ twins than in the DZ twins indicating that genes affect the association between all variables.

\section{Model fitting}

The likelihood ratio test was first compared with the saturated model (ETable 2A Online Data Supplement) and then with the ACE model (ETable 2B, with best likelihood among quantitative genetic models). A statistically non-significant drop in fit $(\mathrm{p}=0.884)$ was observed when comparing the AE model against the ACE model, making the AE model the most parsimonious/final model (ETable 2B).

\section{Quantitative genetic model}

Figure 2 and Table 3 presents the correlation between asthma and $\mathrm{FE}_{\mathrm{NO}}$ separated into genetic and environmental sources. These were factors uniquely related to allergen-specific IgE level, factors unique to eosinophils, factors shared by allergen-specific IgE level and eosinophils, and factors shared between asthma and $\mathrm{FE}_{\mathrm{NO}}$, as estimated in the (best-fitting) AE model (Online Supplemental method outlines how the separation into unique and shared sources has been achieved).

In the best-fitting $\mathrm{AE}$ model, a significant phenotypic correlation, $\mathrm{r}_{\mathrm{ph}}$, was noted between asthma and $\mathrm{FE}_{\mathrm{NO}}\left(\mathrm{r}_{\mathrm{ph}}=0.19\right.$; Table 3$)$. The part of the phenotypic correlation, which can be attributable to additive genetic effects, $r_{p h-a}$, due to allergen-specific IgE level was statistically significant $\left(r_{\mathrm{ph}-\mathrm{a}}=0.10\right)$ and accounted for half $(54 \%)$ of the correlation between asthma and $\mathrm{FE}_{\mathrm{NO}}$. All other estimates were non-significant.

Other quantitative genetic models (ACE, ADE and $\mathrm{CE}$ ), the path coefficients from the AE model, as well as the heritability estimates, are shown in Online Data Supplement, ETable 3, ETable 4A-B.

Twin correlations and results from the quantitative genetic models obtained when the categorical variable $\mathrm{IgE}$ positive was used instead of allergen-specific IgE level can be found in the Online Supplemental material, ETables 5-6. Overall, the results using the categorical IgE positive were very similar to the results obtained from the continuous allergen-specific IgE level.

\section{Discussion}


In this population-based twin study, we disentangled the genetic and environmental sources of covariation between asthma and $\mathrm{FE}_{\mathrm{NO}}$ by analysing the effect of blood eosinophils and allergen-specific IgE-level. More than half $(54 \%)$ in the total covariance between $\mathrm{FE}_{\mathrm{NO}}$ and asthma was due to genetically driven effects of the IgE level to airborne allergens. Thus, our results indicate that genetically driven allergen-specific IgE level, but not blood eosinophil counts, is part of the same underlying construct that creates significant correlation between asthma and $\mathrm{FE}_{\mathrm{NO}}$ in schoolchildren.

This study provides further understanding of genetic influence from the allergen-specific IgE level on $\mathrm{FE}_{\mathrm{NO}}$ in children with asthma. Complex genetic inheritance in asthma susceptibility has been reported, where more than one hundred genetic variants have been implicated ${ }^{36}$. Although just a subset of these genetic variants has been replicated, the genetic contribution to the asthma and $\mathrm{FE}_{\mathrm{NO}}$ association seems unclear ${ }^{21}$. Genetic studies have found a link between $\mathrm{FE}_{\mathrm{NO}}$ values and a few genetic loci ${ }^{37,38}$ and the genetics of the IL-4/IL-13 pathway have been linked to IgE levels of childhood asthma ${ }^{39,40}$. Moreover, gene expression profiles relating to eosinophilic and $\mathrm{T}$ cell pathway have been shown to associate with total IgE levels in children with asthma 41. Thus, genetic variants have been linked to $\mathrm{FE}_{\mathrm{NO}}$, the allergen-specific IgE level, eosinophils and (allergic) asthma, but not all have been combined in a single study in humans. Here, we show that allergen-specific IgE level, highly impacts the asthma $\mathrm{FE}_{\mathrm{NO}}$ association by a genetic component. This may give us a hint of including IgE-diagnostics when treating and managing asthma according to $\mathrm{FE}_{\mathrm{NO}}$-levels in the future.

Previous twin research on asthma phenotypes has applied bivariate modelling to their data ${ }^{20,42-45}$, thereby separating the covariance of genetic and environmental determinants from two sources. Results within these bivariate studies point to a large extent of a common genetic background between asthma phenotypes ${ }^{42-45}$. Here, we include a multivariate modelling with four different sources to investigate whether they share common genetic and/or environmental origins. The advantage of using a multivariate over a bivariate model is that the relationships between several variables can be found simultaneously. Allergen-specific IgE level can be considered a cause of allergic asthma as it is early involved in the inflammatory process which also implicates an increase in eosinophils ${ }^{46}$. Here we found significant genetic influence from allergen-specific $\operatorname{IgE}$ level but not from eosinophils, indicating increasing $\mathrm{FE}_{\mathrm{NO}}$ level reflect dominant type 2 asthma activated by inflammatory cytokines IL-4 and IL-13, but not IL- ${ }^{46}$. Interestingly, Thomsen et al. studied the covariance between $\mathrm{FE}_{\mathrm{NO}}$ and total $\mathrm{IgE}$ and found that $93 \%$ of the phenotypic correlation could be explained by genetic factors ${ }^{44}$. Thus, previous results point to the fact that genetics play an important role in the allergic asthma phenotype. However, caution is warranted when generalizing our results to subjects other than children, since reports show an age-dependent interaction between sensitization and elevated eosinophil levels in asthma $\operatorname{cases}^{47}$.

The major strength of our study is that we used a population-based twin sample of children. We have also used reliable objective biomarkers and the asthma status was based on definitions from the ISAAC study ${ }^{48}$. Another strength of our study is that we included both a continuous and dichotomous IgE variable on sensitization to aeroallergens. This continuous measure enabled us to utilize all the information about the allergen-specific $\operatorname{IgE}$ level variable by maximizing the statistical power. Levels below $0.35 \mathrm{k} \mathrm{U}_{\mathrm{A}} / \mathrm{L}$ can provide additional prognostic information, since results have shown that children who show low sensitization (i.e., $0.10-0.34 \mathrm{kU}_{\mathrm{A}} / \mathrm{L}$ ) to food allergens in infancy seem to have an increased probability of sensitization to aeroallergens in later life ${ }^{49}$. Furthermore, we adjusted for age, sex and ICS use and we re-weighted the analyses by sampling probability. We assumed that the tobacco use would be minor since of the age of the children, thus we did not include it as a covariate. Limitations include the inherently low power of the classical twin method to detect effects of a shared environment. This may partly explain the absence of shared environmental factors, C, even though we used a population-based twin sample. Factors that are shared within twin pairs, such as socio-economic status, that we not did control for, would end up as $\mathrm{C}$ in the models. One might further question the generalizability of the results from twin studies to the general population. Twins differ from singletons in that they are, on average, born smaller; however, we have previously shown that, after taking gestational age into account, twins are not at a higher risk of asthma ${ }^{50}$.

Asthma is a complex disease characterized by a set of genetically heterogeneous phenotypes. As new pheno- 
types for asthma are discovered, twin studies provide a first effort in determining the contribution of genetic and environmental factors to these traits ${ }^{51}$. We are not aware of any other studies that have estimated the proportion of covariance by genetic and environmental effects of inflammatory markers (i.e., allergenspecific IgE level and eosinophils) on the asthma vs. $\mathrm{FE}_{\mathrm{NO}}$ association. The source of the high variability in individual $\mathrm{FE}_{\mathrm{NO}}$ levels in asthmatics is largely unknown, but the present study results may give a partial explanation for this heterogeneity. Thus, the biological background of inflammation should be considered for future personalized medicine.

\section{Conclusions}

This study provides further understanding of genetic influence from allergen-specific IgE-level, but not blood eosinophils, on the $\mathrm{FE}_{\mathrm{NO}}$ asthma association. The results presented here shed new light on the he clinical heterogeneity of $\mathrm{FE}_{\mathrm{NO}}$ values in asthmatic children. As a next step this could encourage omic-studies taking the allergen-specific IgE level into account when investigating inflammation-markers in children with asthma.

Acknowledgments: Swedish Research Council grant no 2018-02640 and through the Swedish initiative for Research on Microdata in the Social and Medical Sciences (SIMSAM) framework grant no 340-2013-5867, grants provided by the Stockholm County Council (ALF-projects and Funding for healthcare personnel), the Strategic Research Program in Epidemiology at Karolinska Institutet, the Swedish Heart-Lung Foundation, the Swedish Asthma and Allergy Association's Research Foundation, the Cancer and Allergy Foundation, Fredrik and Ingrid Thuring's Foundation, King Gustaf V 80th Birthday Foundation and Stiftelsen Frimurare Barnahuset Stockholm. Competing financial interests: M van Hage has received lecture fees from Thermo Fisher Scientific.

\section{Impact statement}

Allergen-specific IgE level impacts the asthma - $\mathrm{FE}_{\mathrm{NO}}$ association by a genetic component. This may give us a hint of including IgE-diagnostics when treating and managing asthma according to $\mathrm{FE}_{\mathrm{NO}}$-levels in the future.

\section{References}

1. Worldwide variation in prevalence of symptoms of asthma, allergic rhinoconjunctivitis, and atopic eczema: ISAAC. The International Study of Asthma and Allergies in Childhood (ISAAC) Steering Committee.Lancet. 1998;351(9111):1225-1232.

2. Global Initiative for Asthma. Global Strategy for Asthma Management and Prevention 2019.https://ginasthmaorg/wp-content/uploads/2019/06/GINA-2019-main-report-June-2019wmspdf 2019;Access 2019.10.30.

3. Woodruff PG, Modrek B, Choy DF, et al. T-helper type 2-driven inflammation defines major subphenotypes of asthma. American journal of respiratory and critical care medicine. 2009;180(5):388-395.

4. Palmer L, Cookson W. Atopy and asthma. In: Bishop T, Sham P, eds.Analysis of multifactorial disease . Oxford: BIOS; 2000.

5. Alving K, Weitzberg E, Lundberg JM. Increased amount of nitric oxide in exhaled air of asthmatics. The European respiratory journal.1993;6(9):1368-1370.

6. Pavlidis S, Takahashi K, Ng Kee Kwong F, et al. "T2-high" in severe asthma related to blood eosinophil, exhaled nitric oxide and serum periostin. The European respiratory journal. 2019;53(1).

7. Ludviksdottir D, Diamant Z, Alving K, Bjermer L, Malinovschi A. Clinical aspects of using exhaled NO in asthma diagnosis and management. Clin Respir J. 2012;6(4):193-207.

8. Shrestha SK, Drews A, Sharma L, Pant S, Shrestha S, Neopane A. Relationship between total serum immunoglobulin E levels, fractional exhaled breath nitric oxide levels and absolute blood eosinophil counts in atopic and non-atopic asthma: a controlled comparative study. Journal of breath research. 2018;12(2):026009. 
9. Persson MG, Zetterstrom O, Agrenius V, Ihre E, Gustafsson LE. Single-breath nitric oxide measurements in asthmatic patients and smokers. Lancet. 1994;343(8890):146-147.

10. Olin AC, Rosengren A, Thelle DS, Lissner L, Bake B, Toren K. Height, age, and atopy are associated with fraction of exhaled nitric oxide in a large adult general population sample. Chest.2006;130(5):1319-1325.

11. Zarogiannis S, Gourgoulianis KI, Kostikas K. Anti-interleukin-5 therapy and severe asthma. N Engl $J$ Med. 2009;360(24):2576; author reply 2577.

12. Kerkhof M, Tran TN, van den Berge M, et al. Association between blood eosinophil count and risk of readmission for patients with asthma: Historical cohort study. PLoS One. 2018;13(7):e0201143.

13. Hancox RJ, Pavord ID, Sears MR. Associations between blood eosinophils and decline in lung function among adults with and without asthma. The European respiratory journal. 2018;51(4).

14. Mogensen I, James A, Malinovschi A. Systemic and breath biomarkers for asthma: an update. Curr Opin Allergy Clin Immunol.2020;20(1):71-79.

15. Martinez FD, Vercelli D. Asthma. Lancet.2013;382(9901):1360-1372.

16. Amaral AFS, Newson RB, Abramson MJ, et al. Changes in IgE sensitization and total IgE levels over 20 years of follow-up. J Allergy Clin Immunol. 2016;137(6):1788-1795.e1789.

17. Barreto M, Villa MP, Monti F, et al. Additive effect of eosinophilia and atopy on exhaled nitric oxide levels in children with or without a history of respiratory symptoms. Pediatr Allergy Immunol.2005;16(1):5258.

18. Los H, Koppelman GH, Postma DS. The importance of genetic influences in asthma. The European respiratory journal.1999;14(5):1210-1227.

19. Posthuma D, Beem AL, de Geus EJ, et al. Theory and practice in quantitative genetics. Twin Res. 2003;6(5):361-376.

20. Thomsen SF, Kyvik KO, Backer V. Etiological relationships in atopy: a review of twin studies. Twin Res Hum Genet. 2008;11(2):112-120.

21. Nordlund B, Lundholm C, Ullemar V, van Hage M, Ortqvist AK, Almqvist C. The STOPPA Twin Study Explains the Exhaled Nitric Oxide and Asthma Link by Genetics and Sensitization. Twin Res Hum Genet.2017;20(4):330-337.

22. Almqvist C, Ortqvist AK, Ullemar V, Lundholm C, Lichtenstein P, Magnusson PK. Cohort Profile: Swedish Twin Study on Prediction and Prevention of Asthma (STOPPA). Twin Res Hum Genet.2015;18(3):273-280.

23. Anckarsater H, Lundstrom S, Kollberg L, et al. The Child and Adolescent Twin Study in Sweden (CATSS). Twin Res Hum Genet.2011;14(6):495-508.

24. Magnusson PK, Almqvist C, Rahman I, et al. The Swedish Twin Registry: establishment of a biobank and other recent developments. Twin Res Hum Genet. 2013;16(1):317-329.

25. Asher MI, Keil U, Anderson HR, et al. International Study of Asthma and Allergies in Childhood (ISAAC): rationale and methods. Eur Respir J. 1995;8(3):483-491.

26. Hedman AM, Gong T, Lundholm C, et al. Agreement between asthma questionnaire and health care register data. Pharmacoepidemiol Drug Saf. 2018;27(10):1139-1146.

27. ATS/ERS recommendations for standardized procedures for the online and offline measurement of exhaled lower respiratory nitric oxide and nasal nitric oxide, 2005. Am J Respir Crit Care Med.2005;171(8):912930. 
28. Ballardini N, Nilsson C, Nilsson M, Lilja G. ImmunoCAP Phadiatop Infant-a new blood test for detecting IgE sensitisation in children at 2 years of age. Allergy. 2006;61(3):337-343.

29. Nilsson SF, Lilja G, Jarnbert-Pettersson H, Alm J. Relevance of low specific IgE levels to egg, milk and peanut in infancy. Clin Exp Allergy. 2018.

30. Lindemalm C, Nordlund B, Ortqvist AK, et al. Associations Between Asthma and Sensitization to Pet or Pollen Allergens in Young Swedish Twins - The STOPPA Study. Twin Res Hum Genet. 2017;20(5):380-388.

31. Purcell S. Statistical Methods in Behavioral Genetics. In: Plomin R, DeFries JC, McClearn GE, P M, eds. Behavioral Genetics . 4th ed. New York, NY: Worth; 2001.

32. Coughlan JL, Gibson PG, Henry RL. Medical treatment for reflux oesophagitis does not consistently improve asthma control: a systematic review. Thorax. 2001;56(3):198-204.

33. Rijsdijk FV, Sham PC. Analytic approaches to twin data using structural equation models. Brief Bioinform. 2002;3(2):119-133.

34. Boker S, Neale M, Maes H, et al. OpenMx: An Open Source Extended Structural Equation Modeling Framework. Psychometrika.2011;76(2):306-317.

35. $R$ Core Team. R: A language and environment for statistical computing. Vienna, Austria: R Foundation for Statistical Computing; 2017.

36. Vercelli D. Discovering susceptibility genes for asthma and allergy.Nat Rev Immunol. 2008;8(3):169-182.

37. van der Valk RJ, Duijts L, Timpson NJ, et al. Fraction of exhaled nitric oxide values in childhood are associated with 17q11.2-q12 and 17q12-q21 variants. J Allergy Clin Immunol. 2014;134(1):46-55.

38. Bouzigon E, Nadif R, Thompson EE, et al. A common variant in RAB27A gene is associated with fractional exhaled nitric oxide levels in adults. Clin Exp Allergy. 2015;45(4):797-806.

39. Kabesch M, Schedel M, Carr D, et al. IL-4/IL-13 pathway genetics strongly influence serum IgE levels and childhood asthma. J Allergy Clin Immunol. 2006;117(2):269-274.

40. Stenberg Hammar K, Hedlin G, Konradsen JR, et al. Subnormal levels of vitamin D are associated with acute wheeze in young children.Acta paediatrica. 2014;103(8):856-861.

41. Virkud YV, Kelly RS, Croteau-Chonka DC, et al. Novel eosinophilic gene expression networks associated with IgE in two distinct asthma populations. Clin Exp Allergy. 2018;48(12):1654-1664.

42. Ferreira MA, O'Gorman L, Le Souef P, et al. Variance components analyses of multiple asthma traits in a large sample of Australian families ascertained through a twin proband. Allergy.2006;61(2):245-253.

43. Lund MB, Kongerud J, Nystad W, Boe J, Harris JR. Genetic and environmental effects on exhaled nitric oxide and airway responsiveness in a population-based sample of twins. Eur Respir J.2007;29(2):292-298.

44. Thomsen SF, Ferreira MA, Kyvik KO, Fenger M, Backer V. A quantitative genetic analysis of intermediate asthma phenotypes.Allergy. 2009;64(3):427-430.

45. Wu T, Boezen HM, Postma DS, et al. Genetic and environmental influences on objective intermediate asthma phenotypes in Dutch twins.Eur Respir J. 2010;36(2):261-268.

46. Matucci A, Vultaggio A, Maggi E, Kasujee I. Is IgE or eosinophils the key player in allergic asthma pathogenesis? Are we asking the right question? Respir Res. 2018;19(1):113.

47. Arbes SJ, Jr., Calatroni A, Mitchell HE, Gergen PJ. Age-dependent interaction between atopy and eosinophils in asthma cases: results from NHANES 2005-2006. Clin Exp Allergy. 2013;43(5):544-551.

48. Asher MI, Keil U, Anderson HR, et al. International Study of Asthma and Allergies in Childhood (ISAAC): rationale and methods. The European respiratory journal. 1995;8(3):483-491. 
49. Nilsson SF, Lilja G, Jarnbert-Pettersson H, Alm J. Relevance of low specific IgE levels to egg, milk and peanut in infancy. Clin Exp Allergy. 2019;49(3):308-316.

50. Ullemar V, Lundholm C, Almqvist C. Twins' risk of childhood asthma mediated by gestational age and birthweight. Clin Exp Allergy.2015;45(8):1328-1336.

51. van Dongen J, Slagboom PE, Draisma HH, Martin NG, Boomsma DI. The continuing value of twin studies in the omics era. Nat Rev Genet.2012;13(9):640-653.

Table 1. Descriptive statistics of the study individuals.

\begin{tabular}{|c|c|c|c|c|}
\hline & $\begin{array}{l}\text { Current } \\
\text { asthma }+, \mathrm{n}= \\
127\end{array}$ & $\begin{array}{l}\text { Current } \\
\text { asthma+, } \mathbf{n}= \\
127\end{array}$ & $\begin{array}{l}\text { No current } \\
\text { asthma, } \mathrm{n}= \\
465\end{array}$ & $\begin{array}{l}\text { No current } \\
\text { asthma, } \mathrm{n}= \\
465\end{array}$ \\
\hline & mean $(\mathrm{SD})$ & n (\%) & mean $(\mathrm{SD})$ & n (\%) \\
\hline Age (y) & 12. $3(1.5)$ & $127(100)$ & $12.6(1.4)$ & $465(100)$ \\
\hline \multicolumn{5}{|l|}{ Sex } \\
\hline Male & & $73(57.5)$ & & $249(53.5)$ \\
\hline Female & & $54(42.5)$ & & $216(46.5)$ \\
\hline \multicolumn{5}{|l|}{$\begin{array}{l}\text { Parental } \\
\text { education }\end{array}$} \\
\hline$<9$ y completed & & 0 & & $0(0)$ \\
\hline 9-12 y completed & & $34(26.8)$ & & $105(22.6)$ \\
\hline$>12$ y completed & & $93(73.2)$ & & $360(77.4)$ \\
\hline \multicolumn{5}{|l|}{$\begin{array}{l}\text { Any parental } \\
\text { asthmaI }\end{array}$} \\
\hline Yes & & $58(45.7)$ & & $72(15.5)$ \\
\hline No & & $66(52.0)$ & & $374(80.4)$ \\
\hline Missing & & $3(2.4)$ & & $19(4.1)$ \\
\hline \multicolumn{5}{|l|}{$\begin{array}{l}\text { Smoking } \\
\text { mother, current }\end{array}$} \\
\hline Yes & & $10(7.9)$ & & $54(11.6)$ \\
\hline No & & $70(55.1)$ & & $220(47.3)$ \\
\hline Missing & & $47(37.0)$ & & $191(41.1)$ \\
\hline \multicolumn{5}{|l|}{ Smoking } \\
\hline \multicolumn{5}{|l|}{ father, current } \\
\hline Yes & & $13(2.4)$ & & $35(7.5)$ \\
\hline No & & $68(53.5)$ & & $252(54.2)$ \\
\hline Missing & & $46(36.2)$ & & $178(38.3)$ \\
\hline \multicolumn{5}{|l|}{$\mathrm{FE}_{\mathrm{NO}}$ : } \\
\hline$[?] 18.25 \mathrm{ppb} .++$ & & $55(43.3)$ & & $92(19.8)$ \\
\hline Arithmetic mean & $25.5(22.1)$ & $122(96.1)$ & $15.8(13.0)$ & $436(93.8)$ \\
\hline Geometric mean & 18.0 & $122(96.1)$ & 12.9 & $436(93.8)$ \\
\hline \multicolumn{5}{|l|}{$\begin{array}{l}\text { Allergen- } \\
\text { specific IgE }\end{array}$} \\
\hline $\begin{array}{l}\text { level, } \mathbf{k} \mathbf{U}_{\mathbf{A}} / \mathbf{L} \\
\text { Arithmetic mean }\end{array}$ & $19.6(26.3)$ & $115(90.6)$ & $7.0(17.9)$ & $433(93.1)$ \\
\hline Geometric mean & 2.3 & $115(90.6)$ & 0.3 & $433(93.1)$ \\
\hline \multicolumn{5}{|l|}{ IgE positive: $\S$} \\
\hline No & & $40(31.5)$ & & $283(60.9)$ \\
\hline Yes & & $75(59.1)$ & & $150(32.3)$ \\
\hline
\end{tabular}




\begin{tabular}{|c|c|c|c|c|}
\hline & $\begin{array}{l}\text { Current } \\
\text { asthma }+, \mathrm{n}= \\
127\end{array}$ & $\begin{array}{l}\text { Current } \\
\text { asthma }+, \mathrm{n}= \\
127\end{array}$ & $\begin{array}{l}\text { No current } \\
\text { asthma, } n= \\
465\end{array}$ & $\begin{array}{l}\text { No current } \\
\text { asthma, } n= \\
465\end{array}$ \\
\hline \multicolumn{5}{|l|}{$\begin{array}{l}\text { Eosinophil cell } \\
\text { count, } 1^{*} 10^{9} \\
\text { counts } / \mathrm{L}\end{array}$} \\
\hline Arithmetic mean & $0.4(0.4)$ & $115(90.6)$ & $0.3(0.3)$ & $422(90.8)$ \\
\hline Geometric mean & 0.3 & $115(90.6)$ & 0.2 & $421(90.5)$ \\
\hline \multicolumn{5}{|l|}{ ICS regularly \# } \\
\hline No & & $83(65.4)$ & & $464(99.8)$ \\
\hline Yes & & $44(34.6)$ & & $1(0.2)$ \\
\hline \multicolumn{5}{|l|}{ Zygosity: } \\
\hline $\mathrm{MZ}$ & & $72(56.7)$ & & $205(44.1)$ \\
\hline $\mathrm{DZ}$ & & $55(43.3)$ & & $260(55.9)$ \\
\hline
\end{tabular}

$\mathrm{SD}=$ Standard Deviation, $\mathrm{n}=$ number of participants, + Asthma is derived from questionnaire by parents answering the question: 'Does your child still have asthma?' ( $\mathrm{n}=20$ had missing value on 'current asthma' but the method allows missing values in the outcome-variables), ++ Parts per billion (ppb), § Sensitization to aeroallergens: $\operatorname{sIgE}[?] 0.35 \mathrm{kU}_{\mathrm{A}} / \mathrm{L}$ to Phadiatop (birch, timothy, mugwort, cat, dog, horse, house dust mites, and mold), ${ }^{\mathrm{P}}$ Based on whether either the mother or father answered 'yes' if they had asthma on the questionnaire, \# Regular use of ICS during the last 12 months.

Table 2. Twin correlations

\begin{tabular}{|c|c|c|c|}
\hline MZ twins & MZ twins & DZ twins & All twins \\
\hline Correlation & Estimate $(95 \% \mathrm{CI})$ & Estimate (95\% CI) & Estimate $(95 \%$ CI $)$ \\
\hline $\begin{array}{l}r_{p h} \text { Eosinophils and } \\
\text { IgE level }\end{array}$ & $0.26(0.12-0.39)$ & $0.24(0.12-0.35)$ & $0.24(0.16-0.33)$ \\
\hline $\begin{array}{l}\mathrm{r}_{\mathrm{ph}} \text { Eosinophils and } \\
\text { Asthma }\end{array}$ & $0.29(0.07-0.51)$ & $-0.05(-0.27-0.18)$ & $0.11(-0.06-0.27)$ \\
\hline $\begin{array}{l}\mathrm{r}_{\mathrm{ph}} \text { Eosinophils and } \\
\mathrm{FE}_{\mathrm{NO}}\end{array}$ & $0.34(0.20-0.47)$ & $0.28(0.17-0.39)$ & $0.30(0.22-0.39)$ \\
\hline $\begin{array}{l}\mathrm{r}_{\mathrm{ph}} \mathrm{IgE} \text { level and } \\
\text { Asthma }\end{array}$ & $0.33(0.13-0.52)$ & $0.29(0.11-0.47)$ & $0.30(0.16-0.44)$ \\
\hline $\mathrm{r}_{\mathrm{ph}} \operatorname{IgE}$ level and $\mathrm{FE}_{\mathrm{NO}}$ & $0.45(0.34-0.57)$ & $0.40(0.30-0.50)$ & $0.42(0.35-0.50)$ \\
\hline $\mathrm{r}_{\mathrm{ph}}$ Asthma and $\mathrm{FE}_{\mathrm{NO}}$ & $0.21(0.00-0.42)$ & $0.17(-0.02-0.35)$ & $0.18(0.04-0.33)$ \\
\hline ICC Asthma & $0.83(0.66-1.00)$ & $0.48(0.14-0.83)$ & NA \\
\hline ICC FE $\mathrm{NO}_{\mathrm{NO}}$ & $0.67(0.56-0.77)$ & $0.34(0.20-0.48)$ & NA \\
\hline ICC IgE level & $0.63(0.55-0.72)$ & $0.26(0.11-0.41)$ & NA \\
\hline ICC Eosinophils & $0.56(0.43-0.69)$ & $0.30(0.14-0.46)$ & NA \\
\hline $\begin{array}{l}\text { CTCT Eosinophils and } \\
\text { IgE level }\end{array}$ & $0.18(0.04-0.32)$ & $0.02(-0.11-0.14)$ & NA \\
\hline $\begin{array}{l}\text { CTCT Eosinophils and } \\
\text { Asthma }\end{array}$ & $0.28(0.06-0.50)$ & $0.00(-0.22-0.21)$ & NA \\
\hline $\begin{array}{l}\text { CTCT Eosinophils and } \\
\text { FE }_{\mathrm{NO}}\end{array}$ & $0.17(0.02-0.32)$ & $0.12(0.00-0.24)$ & NA \\
\hline $\begin{array}{l}\text { CTCT IgE level and } \\
\text { Asthma }\end{array}$ & $0.29(0.10-0.47)$ & $0.09(-0.11-0.29)$ & NA \\
\hline $\begin{array}{l}\text { CTCT IgE level and } \\
\text { FE }_{\mathrm{NO}}\end{array}$ & $0.32(0.20-0.45)$ & $0.14(0.02-0.26)$ & NA \\
\hline
\end{tabular}




\begin{tabular}{llll}
\hline MZ twins & MZ twins & DZ twins & All twins \\
\hline CTCT Asthma and & $0.17(-0.04-0.39)$ & $-0.08(-0.28-0.12)$ & NA \\
FE $_{\text {NO }}$ & & & \\
\hline
\end{tabular}

bold $=$ statistically significantly different from zero. $r_{\mathrm{ph}}=$ phenotypic correlation, i.e. the correlation between variables within individuals, within-twin/cross-trait. ICC $=$ intra-class correlation, i.e. the correlation between the same variable measured in one twin and in her co-twin, cross-twin/within-trait. CTCT $=$ crosstwin/cross-trait correlation, i.e. the correlation between one variable in one twin and another in the co-twin, $\mathrm{IgE}$ level=continuous value of allergen-specific IgE level. Note: Correlations adjusted for covariates sex, age at examination, and ICS-medication (asthma not adjusted for ICS).

Table 3. Results from multivariate modeling. Phenotypic correlation from best-fitting model; due to Asthma and $\mathrm{FE}_{\mathrm{NO}}$ and/or from Eosinophils and $\operatorname{IgE}$ level.

\begin{tabular}{|c|c|c|}
\hline & $\mathbf{A E}$ & $\mathrm{AE}-$ relative contributions \\
\hline total $r_{\mathrm{ph}}$ & $0.19(0.05-0.33)$ & NA \\
\hline $\mathrm{r}_{\mathrm{ph}-\mathrm{a}}$ & $0.14(-0.02-0.29)$ & $0.73(0.18-1.27)$ \\
\hline$r_{p h-e}$ & $0.05(-0.05-0.16)$ & $0.27(-0.27-0.82)$ \\
\hline $\mathrm{r}_{\mathrm{ph}-\mathrm{a}}:$ IgE level & $0.10(0.03-0.18)$ & $0.54(0.03-1.06)$ \\
\hline $\mathrm{r}_{\mathrm{ph}-\mathrm{a}}$ : Eosinophils & $0.01(-0.02-0.04)$ & $0.05(-0.11-0.21)$ \\
\hline$r_{p h-a}$ : Shared between IgE level and eosinophils & $0.02(-0.01-0.06)$ & $0.13(-0.05-0.32)$ \\
\hline $\mathrm{r}_{\mathrm{ph}-\mathrm{a}}:$ Asthma and $\mathrm{FE}_{\mathrm{NO}}$ & $-0.00(-0.15-0.15)$ & $-0.00(-0.78-0.78)$ \\
\hline $\mathrm{r}_{\mathrm{ph}-\mathrm{e}}:$ IgE level & $0.01(-0.02-0.04)$ & $0.07(-0.11-0.24)$ \\
\hline $\mathrm{r}_{\mathrm{ph}-\mathrm{e}}$ : Eosinophils & $-0.01(-0.04-0.03)$ & $-0.04(-0.23-0.16)$ \\
\hline$r_{p h-e}$ Shared between IgE level and eosinophils & $0.00(-0.01-0.02)$ & $0.01(-0.06-0.09)$ \\
\hline $\mathrm{r}_{\mathrm{ph}-\mathrm{e}}:$ Asthma and $\mathrm{FE}_{\mathrm{NO}}$ & $0.04(-0.05-0.14)$ & $0.23(-0.26-0.73)$ \\
\hline
\end{tabular}

$\mathrm{r}_{\mathrm{ph}}=$ phenotypic correlation, $\mathrm{r}_{\mathrm{ph}-\mathrm{a}}=$ part of phenotypic correlation which is attributable to additive genetic effect, $r_{p h-e}=$ part of phenotypic correlation which is attributable to unique environmental effect, $\operatorname{IgE}$ level=continuous value of allergen-specific $\mathrm{IgE}$ level, $\mathrm{NA}=$ not applicable. bold=statistically significantly different from 0 .

Figure 1. Cholesky AE model. Path diagram of association within one individual. Capital A and E refer to latent factors, lower-case a and e refer to path coefficients onto the observed variables. Observed variables are depicted with a square. IgE level=continuous value of allergen-specific IgE level. Note: Variances of latent factors not depicted, but assumed fixed at 1 .

Figure 2. Explained correlation between asthma and $\mathbf{F E}_{\mathbf{N O}}$, re-weighted by sampling probability and adjusted for ICS-use. The height of the bar represents the phenotypic correlation, $\mathrm{r}_{\mathrm{ph}}$. A = Additive genetic effects, $\mathrm{E}=$ unique environmental effects. The color coding represents additive genetic effects, $\mathrm{r}_{\mathrm{ph}-\mathrm{a}}$, or unique environmental effects, $r_{p h-e}$, on the total $r_{p h}$, IgE level=continuous value of allergen-specific $\operatorname{IgE}$ level.

\section{Hosted file}

Figures_200602_AH.docx available at https://authorea.com/users/329932/articles/456811genetic-effects-of-inflammation-markers-on-exhaled-nitric-oxide-in-schoolchildren-withasthma-a-twin-study 